\title{
Lack of High Affinity Fiber Receptor Activity Explains the Resistance of Ciliated Airway Epithelia to Adenovirus Infection
}

\author{
Joseph Zabner, ${ }^{\star}$ Paul Freimuth, ${ }^{\ddagger}$ Aurita Puga, ${ }^{\star}$ Alfredo Fabrega, ${ }^{\star}$ and Michael J. Welsh* \\ Howard Hughes Medical Institute, Department of Internal Medicine, Department of Physiology and Biophysics, and Department of \\ Physiology and Biophysics and Department of Surgery, University of Iowa College of Medicine, Iowa City, Iowa 52242; and ${ }^{\ddagger}$ Brookhaven \\ National Laboratory, Biology, Building 463, Upton, New York 11973
}

\begin{abstract}
Although recombinant adenoviruses are attractive vectors for gene transfer to airway epithelia, they have proven to be relatively inefficient. To investigate the mechanisms of adenovirus-mediated gene transfer to airway epithelia, we examined the role of adenovirus fiber and penton base, the two proteins involved in attachment to and entry of virus into the cell. We used human airway epithelia grown under conditions that allow differentiation and development of a ciliated apical surface that closely resembles the in vivo condition. We found that addition of fiber protein inhibited virus binding and vector-mediated gene transfer to immature airway epithelia, as well as to primary cultures of rat hepatocytes and HeLa cells. However, fiber protein had no effect on vector binding and gene transfer to ciliated airway epithelia. We obtained similar results with addition of penton base protein: the protein inhibited gene transfer to immature epithelia, whereas there was no effect with ciliated epithelia. Moreover, infection was not attenuated with an adenovirus containing a mutation in penton base that prevents the interaction with cell surface integrins. These data suggest that the receptors required for efficient infection by adenovirus are either not present or not available on the apical surface of ciliated human airway epithelia. The results explain the reason for inefficient gene transfer and suggest approaches for improvement. (J. Clin. Invest. 1997. 100: 1144-1149.) Key words: gene transfer • adenovirus • cystic fibrosis $\bullet$ fiber $\bullet$ penton base
\end{abstract}

\section{Introduction}

Several considerations have suggested that recombinant adenoviruses would be attractive vectors for gene transfer to airway epithelia $(1,2)$. One of the foremost considerations was the fact that respiratory tract infections with type $\mathrm{C}$ adenovirus are common, representing about $3-5 \%$ of all respiratory infections in children. Second, almost all adults have antibodies to type $\mathrm{C}$ adenovirus (3). In addition, transmission of wild-type

Address correspondence to Michael J. Welsh, M.D., Howard Hughes Medical Institute, University of Iowa College of Medicine, 500 EMRB, Iowa City, IA 52242. Phone: 319-335-7619; FAX: 319-335-7623; E-mail: mjwelsh@blue.weeg.uiowa.edu

Received for publication 20 February 1997 and accepted in revised form 9 June 1997.

J. Clin. Invest.

(C) The American Society for Clinical Investigation, Inc. 0021-9738/97/09/1144/06 \$2.00

Volume 100, Number 5, September 1997, 1144-1149

http://www.jci.org adenovirus occurs by aerosolization, suggesting that delivery to airway should be feasible. Human alveolar epithelia, more specifically Type II cells, have been found by in situ hybridization to be infected with wild-type adenovirus (4). Moreover, evidence of viral replication in the bronchial epithelia of cotton rats and human autopsy specimens has been shown $(5,6)$. However, despite initial optimism, the efficiency of gene transfer to human airway epithelia in vivo has been limited (7-11).

Evaluation of the efficiency of gene transfer to human airway epithelia clearly depends upon the model system used and the experimental methods that are employed. Previous work has shown that when human airway epithelial cells are cultured on permeable filter supports at the air-liquid interface, they generate an epithelium with many properties of native airway epithelia (12). We found that when airway epithelia were allowed to mature in culture they became relatively resistant to infection by adenovirus vectors (13). This difficulty in gene transfer has also been reported in rabbit and human explants (14), in a human xenograft model (15), and in the upper airways of animals $(13,14)$. In contrast, it is relatively easy to infect airway cells grown on culture dishes (our unpublished observation).

The first steps in adenovirus infection are thought to involve primarily two proteins in the capsid: fiber and penton base $(3,16)$. The fiber protein is important for binding to a high affinity fiber receptor. In KB, A459, and HeLa cells, this receptor is thought to be present in the range of 3,000-6,000 receptors per cell (17-19). However, the receptor for fiber has not been identified and it is thought to be different for various serotypes of adenovirus (19). As a result, it has been difficult to assess whether resistance to infection by various cells is caused by the lack of fiber receptor. However, mouse fibroblasts, which are resistant to adenovirus infection, do not bind radioactive fiber protein suggesting that the lack of a receptor is responsible for resistance to infection (20). Binding of penton base to cell surface integrins may also play a role in adenovirus infection (21). In HeLa and 293 cells, penton base binds $\alpha v$ integrins which mediates virus internalization $(16,21-$ 23). Penton base has also been linked to the ability of adenovirus to escape the endosomal compartment and perhaps to carry the viral DNA to the nucleus $(16,24,25)$. Attempts to correlate the presence of $\alpha v$ integrins with the efficiency of adenovirus-mediated gene transfer have yielded varying results $(26,27)$. In a preliminary study, we found that primary cultures of rat hepatocytes were very efficiently transfected but did not express $\alpha \nu \beta 5$ integrins (28). Human airway epithelia express $\alpha \nu \beta 5$ integrins on the basal cells and on the basolateral surface of columnar cells, but the significance for adenoviral infection is uncertain (15).

At first it seems surprising that adenovirus vectors do not have greater efficiency at infecting airway epithelia because airway cells are thought to be a target for wild-type adenovirus 
(29). The poor efficiency of infection raises the question of how type $\mathrm{C}$ adenovirus infects airway epithelia. The goal of this study was to use a model relevant to human airway epithelia and address questions about the role of fiber and penton base in adenovirus infection.

\section{Methods}

Airway epithelial and primary rat hepatocytes. Airway epithelial cells were obtained from surgical polypectomies of non-cystic fibrosis patients or from trachea and bronchi of lungs removed for organ donation. Cells were isolated by enzyme digestion as described previously (30). Freshly isolated cells were seeded at a density of $5 \times 10^{5}$ cells/ $\mathrm{cm}^{2}$ onto collagen-coated permeable membranes $\left(0.6 \mathrm{~cm}^{2}\right.$, MilliporeInserts). The cells were maintained at $37^{\circ} \mathrm{C}$ in a humidified atmosphere of $5 \% \mathrm{CO}_{2}$ and air. $24 \mathrm{~h}$ after plating, the mucosal media was removed and the cells were allowed to grow at the air-liquid interface $(12,31)$. The culture medium was a mixture of $49 \%$ DME, $49 \%$ Ham's F12, and 2\% Ultraser G (Sepracor Inc., Marlborough, MA). Penicillin $(100 \mathrm{U} / \mathrm{ml})$ and streptomycin $(100 \mu \mathrm{g} / \mathrm{ml})$ were added to the media.

Primary cultures of rat hepatocytes were isolated as described by Berry and Friend (32). The isolated cells were placed in culture medium consisting of Eagle's MEM 75\% and Waymouth's 25\% supplemented with $10 \%$ FCS, $2 \mathrm{mM}$ L-glutamine, $4 \mu \mathrm{g} / \mathrm{ml}$ dexamethasone (Sigma Chemical Co., St. Louis, MO), $10 \mathrm{ng} / \mathrm{ml}$ triiodothyronine (Sigma Chemical Co.), $50 \mathrm{ng} / \mathrm{ml}$ EGF (Sigma Chemical Co.) and ITS Universal Culture Supplement (Collaborative Biomedical Products, Bedford, MA) and seeded onto collagen-coated 24-well plates at $4 \times$ $10^{5}$ cells $/ \mathrm{cm}^{2}$.

Virus preparation. The construction and preparation of $\mathrm{Ad} 2 /$ $\beta$ Gal-2 has been described previously (33). In Ad2/3Gal-2, the viral cytomegalovirus promoter drives expression of $\beta$-galactosidase. We also used wild-type 2 adenovirus (Ad2wt) ${ }^{1}$ and wild-type 2 adenovirus in which the RGD motif of penton base was mutated to RAE (Ad2RAE) (23). For some studies adenovirus was labeled by production in 293 cells in methionine-free medium containing $1 \mathrm{mCi} / 100 \mu \mathrm{l}$ of $\left[{ }^{35}\right.$ S $]$ methionine (Amersham Life Science, Arlington Heights, IL). Fiber protein and penton base protein were prepared as described previously (23).

Viral infection and binding assays. Epithelia were allowed to reach confluence and develop a transepithelial electrical resistance $\left(R_{t}\right)$, indicating the development of tight junctions and an intact barrier. All epithelia had values of $R_{t}>500 \Omega \cdot \mathrm{cm}^{2}$. 3-14 d after seeding, dilutions of the recombinant viruses (in PBS) ranging from 0 to 50 moi were added to the apical surface. After the indicated incubation time, the viral suspension was removed and the monolayers were rinsed twice with PBS. After infection, the monolayers were incubated at $37^{\circ} \mathrm{C}$ for an additional $30-72 \mathrm{~h}$. Transepithelial resistance was measured with an ohmmeter (EVOM ${ }^{\mathrm{TM}}$; World Precision Instruments, Inc., Sarasota, FL) before infection, and $\mathrm{R}_{\mathrm{t}}$ was not altered by application of virus.

To assess binding on airway epithelia, the monolayers were incubated for $30 \mathrm{~min}$ at $4{ }^{\circ} \mathrm{C}$ with the $\left[{ }^{35} \mathrm{~S}\right]$ methionine-labeled adenoviruses. Only at 2,500 particles per cell were we able to quantitate binding above background. Cell-associated $\left[{ }^{35} \mathrm{~S}\right]$ adenovirus was evaluated in sextuplicates by liquid scintillation counting (LKB Wallac, Gaithersburg, MD). As a control to assess binding, a cell suspension $\left(10^{6}\right.$ cells per milliliter) of freshly isolated rat hepatocytes or HeLa cells were incubated with dilutions of $\left[{ }^{35} \mathrm{~S}\right]$ methionine-labeled adenoviruses ranging from 25 to 2,500 particles per cell, for $30 \mathrm{~min}$ at $4^{\circ} \mathrm{C}$ in a

1. Abbreviations used in this paper: Ad2RAE, wild-type 2 adenovirus in which the RGD motif of penton base is mutated to RAE; Ad2wt, wild-type 2 adenovirus; $R_{t}$, transepithelial electrical resistance. rotating mixer. The virus was removed and followed by two thorough rinses with Eagle's MEM.

Measurement of $\beta$-galactosidase activity. We measured total $\beta$-galactosidase activity using a commercially available method (GalactoLight $^{\mathrm{TM}}$; Tropix Inc., Bedford, MA). Briefly, after rinsing with PBS, cells were removed from filters by incubation with a $120-\mu l$ lysis buffer (25 mM Tris-phosphate, pH 7.8; 2 mM DTT; 2 mM 1,2-diaminocyclohexane-N,N, $\mathrm{N}^{\prime}, \mathrm{N}^{\prime}$-tetraacetic acid; $10 \%$ glycerol; and $1 \%$ Triton X-100) for 15 min. Light emission was quantified in a luminometer (Analytical Luminescence Laboratory, San Diego, CA).

Determination of wild-type Ad-2 infection. We estimated the number of cells infected with Ad2wt and Ad2RAE by antihexon staining. HeLa cells and airway epithelia cultured on permeable filter supports were studied $30 \mathrm{~h}$ after infection. They were fixed with acetone/methanol and stained with a polyclonal FITC-labeled antihexon antibody (Chemicon International, Inc., Temecula, CA). Hexon positive cells were counted by fluorescence microscopy of the monolayers. This method allows detection of infected cells by staining for the most abundant adenovirus protein, hexon, and has better sensitivity than use of reporter genes such as $\beta$-galactosidase.

\section{Results}

Role of fiber receptor in Ad2 infection of ciliated airway epithelia. We investigated the mechanism of adenovirus infection of the airways by using primary cultures of human airway epithelia grown on permeable filter supports. We previously showed that by $3 \mathrm{~d}$ after seeding, the epithelial cells appeared confluent, the cells varied in size, and most appeared to have short microvilli (13). In addition, the cells formed tight junctions generating a transepithelial electrical resistance. However, by 10-14 d after seeding the epithelia had matured so that most of the cells were covered with cilia. Using this model system, we previously showed that mature human airway epithelia were resistant to infection by adenovirus and that the resistance could be partially overcome by increasing the incubation time (13).

To evaluate the relative contribution of the fiber receptor to infection, we applied Ad2/3Gal-2 to either immature (3 d after seeding) or mature (14 d after seeding) airway epithelia. The epithelia were incubated with 50 moi Ad2/3Gal-2 for either $30 \mathrm{~min}$ or $12 \mathrm{~h}$. With a $30 \mathrm{~min}$ incubation, the total enzyme activity for immature airway was $2.84 \pm 0.09 \times 10^{6}$ light units (L.U.) $/ 10^{6}$ cells compared with $7.8 \pm 0.43 \times 10^{5}$ L.U. $/ 10^{6}$ cells for mature epithelia. With a $12 \mathrm{~h}$ incubation, the total enzyme activity for immature airway was $6.36 \pm 0.06 \times 10^{6}$ L.U. $/ 10^{6}$ cells compared with $3.53 \pm 0.1 \times 10^{6}$ L.U. $/ 10^{6}$ cells for mature epithelia. To specifically evaluate the contribution of the fiber receptor, epithelia were also treated with $70 \mu \mathrm{g} / \mathrm{ml}$ of fiber protein. Fig. 1 shows that with immature airway epithelia, fiber protein significantly blocked adenovirus-mediated gene transfer and expression regardless of the incubation time. In contrast, in mature ciliated airway epithelia fiber had no significant effect after infection for either $30 \mathrm{~min}$ or $12 \mathrm{~h}$. As a control, Fig. 1 shows that fiber inhibited $>85 \%$ of the infection of HeLa cells and primary cultures of rat hepatocytes.

To evaluate further the interaction between fiber protein and fiber receptor, we measured binding of $\left[{ }^{35} \mathrm{~S}\right] \mathrm{methionine-}$ labeled Ad2/ $\beta$ Gal-2. In airway epithelia we applied 2,500 adenovirus particles per cell. Fig. $2 A$ shows that with immature airway epithelia, adenovirus binding was blocked by addition of excess fiber protein. In contrast, fiber protein had no affect on binding to mature airway epithelia. For comparison and as a control, we measured binding of $\left[{ }^{35} \mathrm{~S}\right]$ methionine-labeled ad- 
A Immature airway epithelia

L.U.

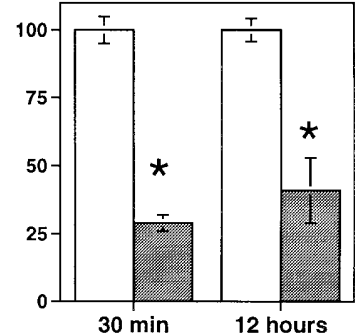

B Mature airway epithelia

L.U.

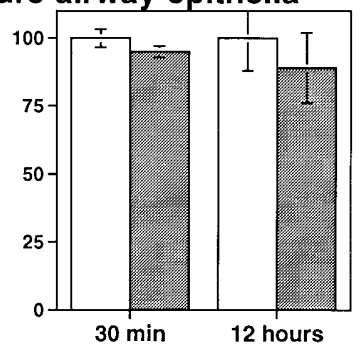

C HeLa and hepatocytes

L.U.

(\% control)

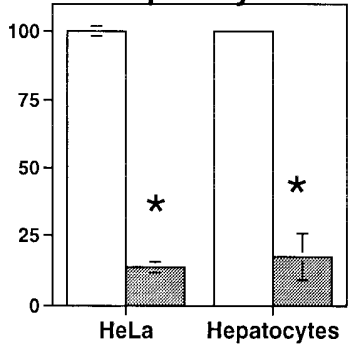

Figure 1. Effect of fiber protein on adenovirusmediated transgene expression by human airway epithelia monolayers. Immature $(A)$ and mature $(B)$ airway epithelia were exposed to 50 moi $\mathrm{Ad} 2 / \beta \mathrm{Gal}-2$ for either $30 \mathrm{~min}$ or $12 \mathrm{~h}$ $(n=12-28)$. The vector was then removed and the epithelia were cultured for two additional days before analysis. $C$ shows data from $\mathrm{HeLa}$ cells and primary cultures of rat hepatocytes $(n=6)$. Data are the percentage of $\beta$-galactosidase activity under control conditions (open bars) and in the presence of fiber protein (shaded bars). Data are mean \pm SEM; in some cases the error bars are obscured by the bars. Asterisk indicates $P<0.01$.

enovirus to primary cultures of rat hepatocytes. Fig. $2 \mathrm{~B}$ shows that adenovirus bound to hepatocytes to a much greater extent (sixfold) than to the immature airway epithelia and 29-fold greater than to mature airway epithelia. Moreover, addition of fiber markedly decreased adenovirus binding in hepatocytes.

We considered the possibility that the reduced fiber-dependent binding to airway epithelia was a result of an abnormality related to the recombinant adenovirus. Therefore, we labeled Ad2/ßGal-2 and Ad2wt and compared binding of the two different viruses to HeLa cells. Fig. 3 shows that both viruses bound to a similar extent and that in both cases addition of fiber protein blocked virus binding.

These data indicate that mature ciliated airway epithelia do not bind adenovirus- 2 through the high affinity fiber receptor. This contrasts with findings in HeLa cells or in primary cultures of rat hepatocytes.

Role of penton base receptor in adenovirus-2 infection of ciliated airway epithelia. We evaluated the relative contribution of the adenovirus penton base on infection of ciliated airway epithelia by applying 50 moi of Ad2/ßGal-2 in either $50 \mu \mathrm{l}$ of PBS or PBS containing $1 \mu \mathrm{g} / \mathrm{ml}$ of penton base protein. For these studies we used either immature ( $3 \mathrm{~d}$ after seeding) or mature (14 d after seeding) epithelia and applied virus for either $30 \mathrm{~min}$ or $12 \mathrm{~h}$. Fig. 4 shows that with immature airway epithelia infected for $30 \mathrm{~min}$, penton base blocked infection by nearly $50 \%$. However, penton base failed to block infection when the immature epithelia were incubated with the virus for $12 \mathrm{~h}$. Moreover, there was no effect of adding penton base on infection of mature airway epithelia. In addition, we were not able to compete adenovirus-mediated gene transfer to airway

A
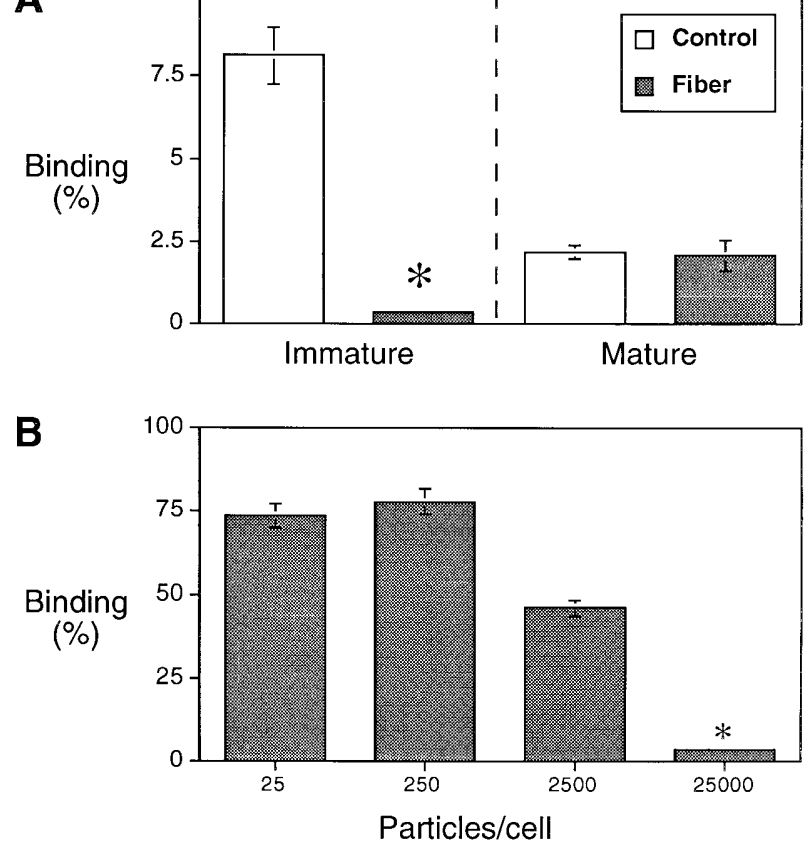

Figure 2. Effect of excess fiber protein on binding of $\left[{ }^{35} \mathrm{~S}\right]$ methioninelabeled adenovirus. $A$ shows the percent of $\mathrm{Ad} 2 / \beta \mathrm{Gal}-2$ binding by immature ( $3 \mathrm{~d}$ ) and mature ( $14 \mathrm{~d}$ ) airway epithelia at a ratio of 2,500 adenovirus particles per cell. Open bars show control conditions and shaded bars show binding in the presence of fiber. $B$ shows the percent of $\mathrm{Ad} 2 / \beta \mathrm{Gal}-2$ binding by primary cultures of rat hepatocytes at different ratios of viral particles per cell. Data are mean \pm SEM, $n=6$. Asterisk indicates $P<0.01$.

epithelia by addition of $4 \mathrm{mg} / \mathrm{ml}$ of an RGD peptide that competes with adenovirus penton base for binding to the integrin receptor. As a control for nonadenovirus specific gene transfer, we applied an antihexon antibody. In all conditions, the antihexon antibody blocked gene transfer to $<1 \%$ control $(n=12$, not shown $)$.

As an additional way of evaluating the interaction of penton base with integrin receptors on the cell surface, we used an adenovirus in which the penton base RGD sequence had been mutated to RAE. This mutation inhibits the penton base- $\alpha \nu \beta 5$ interaction (23). We infected mature human airway epithelia

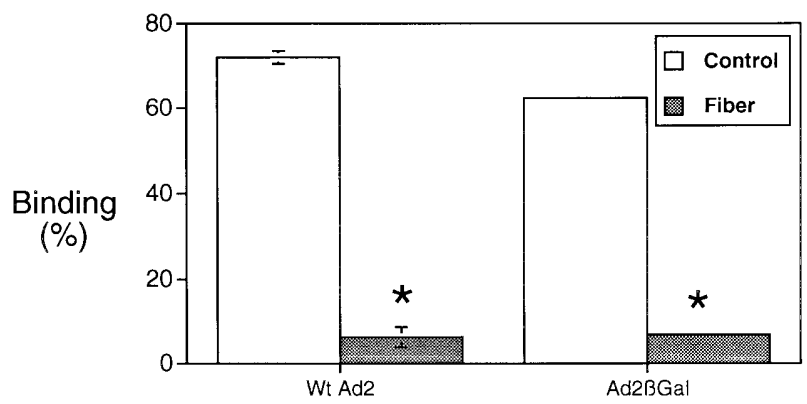

Figure 3. Binding of recombinant and wild-type adenovirus to HeLa cells. Data are percentage of $\left[{ }^{35} \mathrm{~S}\right]$ methionine-labeled wild-type Ad2 and Ad2/ $\beta$ Gal- 2 at a ratio of 250 adenovirus particles per cell. Open bars indicate control conditions and shaded bars binding in the presence of fiber. Data are mean \pm SEM, $n=6$. Asterisk indicates $P<0.01$. 
A Immature Airway

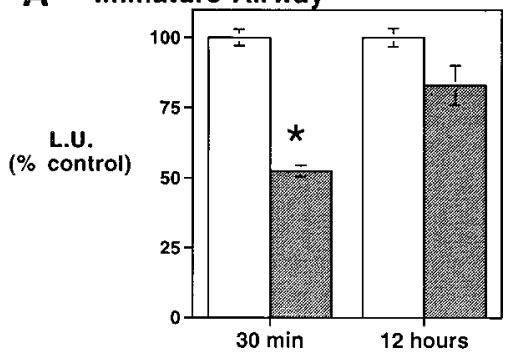

B Mature Airway

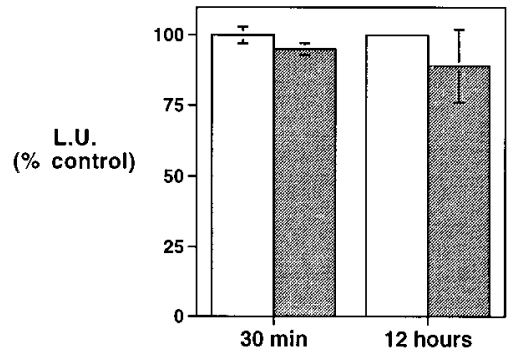

Figure 4. Effect of penton base protein on adenovirus-mediated transgene expression by human airway epithelia. $3(A)$ and 14 (B) $\mathrm{d}$ after seeding, epithelia were exposed to 50 moi Ad2/ $\beta$ Gal-2 for either $30 \mathrm{~min}$ or $12 \mathrm{~h}$. Vector was then removed and the epithelia were cultured for two additional days before analysis. Data are percentage of $\beta$-galactosidase activity under control conditions (open bars) or in the presence of penton base (shaded bars). Data are mean \pm SEM, $n=12$. Asterisk indicates $P<0.01$.

with either Ad2wt or Ad2RAE. Figs. 5 and 6 show that both viruses infected a similar number of airway epithelial cells. As a control, Fig. 6 shows that Ad2-RAE was less effective than Ad2wt at infecting HeLa cells.

\section{Discussion}

Our results suggest that neither adenovirus fiber nor penton base play an important role in infection of mature airway epithelia. This contrasts with the importance of these proteins in adenovirus infection of many cell culture models used to study mechanisms of adenovirus infection. Our observations also impact several previous reports. First, the data confirm results from our previous studies showing that mature ciliated airway epithelia can be infected by an adenovirus vector, but prolonged incubation times are required. Second, these data explain, at least in part, the poor efficiency of adenovirus-mediated gene transfer to the airway in human studies $(7,9,11)$. Third, the results may explain our finding of efficient gene transfer to human nasal epithelia in vivo when the epithelium was unintentionally injured by an applicator (11). They also explain the finding that intentional injury of airway epithelia studied in vitro increased the efficiency of gene transfer (34). In those in vivo and in vitro studies, mechanical injury may have removed ciliated cells which exposes basal cells and stimulated proliferation of nonciliated immature cells. Those cells might more readily take up the virus because they express the relevant receptors.

Our data suggest that limited binding of adenovirus to the apical surface of mature airway epithelia is an important barrier for adenovirus infection. The data suggest that the apical surface may not have the fiber receptors required for efficient
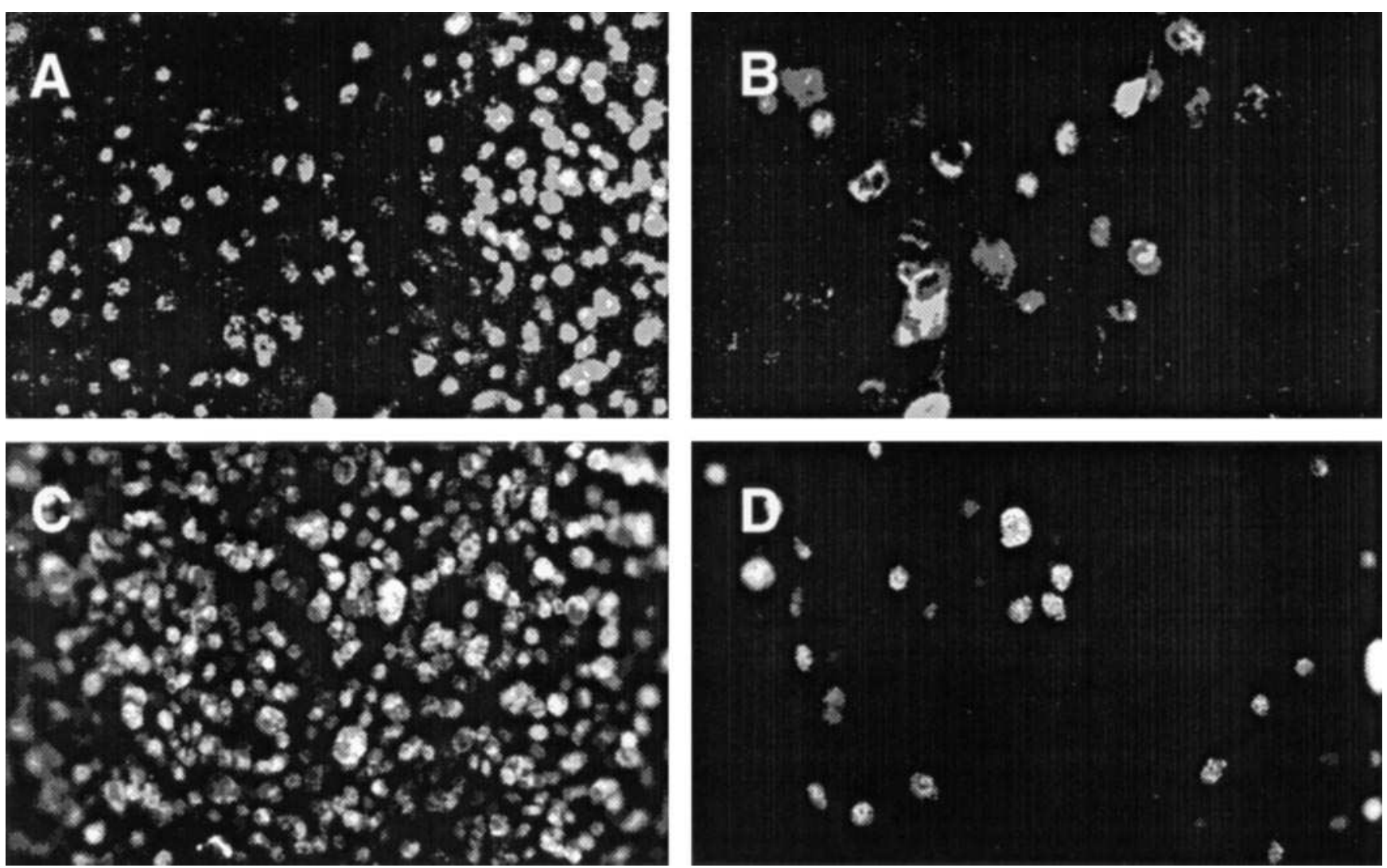

Figure 5. Infection of primary cultures of mature human airway epithelia by wild-type adenovirus 2 or the RAE penton base mutant. Epithelia were studied $14 \mathrm{~d}$ after they were seeded when they were confluent and differentiated. Ad2wt or Ad2RAE (50 moi) were applied to apical surface of epithelia $\left(\sim 5 \times 10^{5}\right.$ cells per epithelium) for $12 \mathrm{~h}$. Vector was then removed and the epithelium was rinsed twice. $30 \mathrm{~h}$ later epithelia were fixed and stained with FITC-labeled antihexon antibody. Figure shows fluorescent micrograph from epithelia infected with Ad2wt $(B)$ or Ad2RAE $(D)$. $A$ and $C$ show DAPI-stained nuclei from epithelia in $B$ and $D$, respectively. 


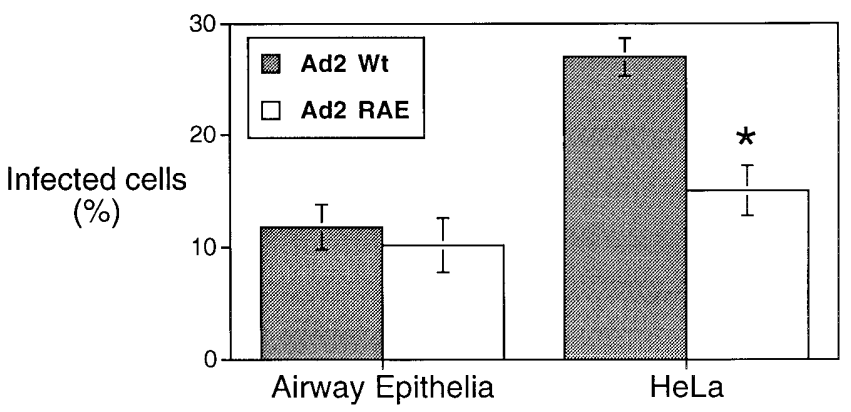

Figure 6. Infection of primary cultures of mature human airway epithelia or HeLa cells by wild-type adenovirus 2 (shaded bars) or the adenovirus with a penton base mutation (open bars). Epithelia were studied $14 \mathrm{~d}$ after seeding when they were confluent and differentiated. HeLa cells were studied $4 \mathrm{~d}$ after seeding. 50 moi of either virus were applied to apical surface of epithelia for $12 \mathrm{~h}$, or 1 moi for 30 min on HeLa cells. Data are mean \pm SEM of percentage of airway epithelia cells expressing hexon, $n=3-6$. Asterisk indicates $P<0.05$.

infection. Because the fiber receptor protein(s) has not yet been identified, we cannot rule out the possibility that the fiber receptor is present but is not accessible because of a physical barrier. It seems unlikely that the cilia, per se, are a physical barrier to infection, because we previously showed that the epithelia developed resistance to infection even before a significant number of cells developed cilia. However, other physical barriers such as mucus, glycolipids, and glycoproteins might be involved. It seemed possible that the infection that we observed after prolonged incubation could result from penetration of a physical barrier by the virus. However, the inability of excess fiber protein to inhibit adenovirus infection after prolonged incubation makes this possibility less likely.

The results also suggest that interactions between the adenovirus penton base and $\alpha \nu \beta 5$ integrins are not essential for infection of human airway epithelia. We found that adenovirusmediated gene transfer to immature airway epithelia was only partially blocked by excess penton base during short incubation times, but when the incubation time was prolonged there was no effect. Moreover, mature airway epithelia were infected as well by an adenovirus that lacks the RGD fibronectin receptor ligand motif as by a wild-type virus. However, our conclusions about the lack of importance of interactions between penton base and integrins in airway epithelia do not rule out the possibility that penton base plays some role in internalization, escape from the endosomal compartment, or delivery of adenovirus DNA to the nucleus. Our data suggest that the lack of $\alpha \nu \beta 5$ integrin observed in ciliated airway epithelia, as compared to basal cells or undifferentiated airway cells, may correlate with resistance to infection (15), but is not likely to be causative. Moreover, we have previously shown that cells that do not express $\alpha \nu \beta 5$ integrins such as primary cultures of rat hepatocytes can be easily infected by adenovirus (28). Finally, distal airways are also involved in cystic fibrosis. It seems possible that binding and uptake could be more efficient in small airways, as the epithelia changes into a more cuboidal type with less ciliated cells (35). Further work is needed to test adenovirus infection of distal airway.

The results of this study suggest that several considerations should be explored in developing adenovirus-mediated gene transfer to airway epithelia. It may be possible to remove phys- ical barriers to increase the contact of adenovirus with the cell membrane. However, our data suggest that such a maneuver alone would probably not be sufficient. In principle, it may be possible to either change the cell or the virus. It might also be possible to induce the cells to express a relevant receptor and/ or to promote internalization of virus which does bind. It is also possible that a different serotype of adenovirus or an adenovirus vector containing new epitopes that target it to a different receptor might show increased binding to the apical surface of airway epithelia in a manner analogous to what has been done with retroviruses (36). Genetic modifications in the adenovirus fiber and/or penton base, could add sequences that improve binding to cells. Wickham et al. (37) modified the fiber protein to add a heparin-binding domain (multiple lysines added to the $\mathrm{C}$ terminus of fiber). This change increased binding to cells through heparin-containing cellular receptors. Cell specific targeting of adenoviral vectors has been achieved by Douglas et al. (38). By conjugating folate to the Fab fragment of a neutralizing antifiber antibody, they were able to ablate the tropism of the virus, and redirect it towards cells expressing folate receptors. The results from these studies suggest that strategies that increase binding to ciliated cell-specific membrane receptors, would increase efficiency of adenovirus-mediated gene transfer. Because the airway epithelia can be targeted specifically by delivery of an aerosol, strategies that involve ubiquitous cellular receptors as a target, or receptors that require stimulation by drugs, could presumably be used without sacrificing specificity.

Added in revision. Since the submission of this paper, a receptor for adenovirus fiber has been identified in HeLa cells (39). The receptor belongs to the immunoglobulin gene superfamily and also functions as a Coxsackie B virus receptor. It will be interesting to examine the relationship between the presence or absence of this receptor and infection by adenovirus.

\section{Acknowledgments}

We thank Pary Weber, Steve Struble, Phil Karp, and Theresa Mayhew for their excellent assistance. We especially appreciate the help of Dr. Mary Schroth. We thank Alan E. Smith and Sam Wadsworth (Genzyme, Framingham, MA) for the gift of wild-type adenovirus and Ad2/ $\beta$ Gal-2. We appreciate the support of the University of Iowa Gene Transfer Vector Core (supported in part by the Roy J. Carver Charitable Trust).

This work was supported by the National Heart Lung and Blood Institute (HL-51670), the Cystic Fibrosis Foundation, and the Roy J. Carver Charitable Trust. J. Zabner is a Parker B. Francis Fellow and a Fellow of the Roy J. Carver Charitable Trust. M.J. Welsh is an Investigator of the Howard Hughes Medical Institute.

\section{References}

1. Crystal, R.G. 1995. Transfer of genes to humans: early lessons and obstacles to success. Science (Wash. DC). 270:404-410.

2. Wilson, J.M. 1996. Molecular medicine: adenovirus as gene-delivery vehicles. N. Engl. J. Med. 334:1185-1187.

3. Ginsberg, H.S. 1984. The Adenoviruses. Plenum Publishing Corp., New York. 605 pp.

4. Hogg, J.C., W.L. Irving, H. Porter, M. Evans, M.S. Dunnill, and K. Fleming. 1989. In situ hybridization studies of adenoviral infections of the lung and their relationship to follicular bronchiectasis. Am. Rev. Respir. Dis. 139:15311535.

5. Prince, G.A., D.D. Porter, A.B. Jenson, R.L. Horswood, R.M. Chanock, and H.S. Ginsberg. 1993. Pathogenesis of adenovirus type 5 pneumonia in cotton rats (Sigmodon hispidus). J. Virol. 67:101-111.

6. Ladenheim, H.S., A.S. Mistchenko, and R. Drut. 1995. Expression of 
early and late adenoviral proteins in fatal adenovirus bronchopneumonia. Pediatr. Pathol. Lab. Med. 15:291-298.

7. Hay, J.G., N.G. McElvaney, J. Herena, and R.G. Crystal. 1995. Modification of nasal epithelial potential differences of individuals with cystic fibrosis consequent to local administration of a normal CFTR cDNA adenovirus gene transfer vector. Hum. Gene Ther. 6:1487-1496.

8. Crystal, R.G., N.G. McElvaney, M.A. Rosenfeld, C.S. Chu, A. Mastrangeli, J.G. Hay, S.L. Brody, H.A. Jaffe, N.T. Eissa, and C. Danel. 1994. Administration of an adenovirus containing the human CFTR cDNA to the respiratory tract of individuals with cystic fibrosis. Nat. Genet. 8:42-51.

9. Knowles, M.R., K.W. Hohneker, Z. Zhou, J.C. Olsen, T.L. Noah, P.C. Hu, M.W. Leigh, J.F. Engelhardt, L.J. Edwards, K.R. Jones, et al. 1995. A controlled study of adenoviral-vector-mediated gene transfer in the nasal epithelium of patients with cystic fibrosis. N. Engl. J. Med. 333:823-831.

10. Zabner, J., L.A. Couture, R.J. Gregory, S.M. Graham, A.E. Smith, and M.J. Welsh. 1993. Adenovirus-mediated gene transfer transiently corrects the chloride transport defect in nasal epithelia of patients with cystic fibrosis. Cell. 75:207-216.

11. Zabner, J., B.W. Ramsey, D.P. Meeker, M.I. Aitken, R.P. Balfour, R.L. Gibson, J. Launspach, R.A. Moscicki, S.M. Richards, T.A. Standaert, et al. 1996. Repeat administration of an adenovirus vector encoding CFTR to the nasal epithelium of patients with cystic fibrosis. J. Clin. Invest. 97:1504-1511.

12. Yamaya, M., W.E. Finkbeiner, S.Y. Chun, and J.H. Widdicombe. 1992. Differentiated structure and function of cultures from human tracheal epithelium. Am. J. Physiol. 262:L713-L724.

13. Zabner, J., B.G. Zeiher, E. Friedman, and M.J. Welsh. 1996. Adenovirus-mediated gene transfer to ciliated airway epithelia requires prolonged incubation time. J. Virol. 70:6994-7003.

14. Grubb, B.R., R.J. Pickles, H. Ye, J.R. Yankaskas, R.N. Vick, J.F. Engelhardt, J.M. Wilson, L.G. Johnson, and R.C. Boucher. 1994. Inefficient gene transfer by adenovirus vector to cystic fibrosis airway epithelia of mice and humans. Nature (Lond.). 371:802-806.

15. Goldman, M.J., and J.M. Wilson. 1995. Expression of alpha v beta 5 integrin is necessary for efficient adenovirus-mediated gene transfer in the human airway. J. Virol. 69:5951-5958.

16. Greber, U.F., M. Willetts, P. Webster, and A. Helenius. 1993. Stepwise dismantling of adenovirus 2 during entry into cells. Cell. 75:477-486.

17. Persson, R., U. Svensson, and E. Everitt. 1983. Virus receptor interaction in the adenovirus system. II. Capping and cooperative binding of virions on hela cells. J. Virol. 46:956-963.

18. Persson, R., C. Wohlfart, U. Svensson, and E. Everitt. 1985. Virusreceptor interaction in the adenovirus system: characterization of the positive cooperative binding of virions on HeLa cells. J. Virol. 54:92-97.

19. Defer, C., M.T. Belin, M.L. Caillet-Boudin, and P. Boulanger. 1990. Human adenovirus-host cell interactions: comparative study with members of subgroups b and c. J. Virol. 64:3661-3673.

20. Roelvink, P.W., I. Kovesdi, and T.J. Wickham. 1996. Comparative analysis of adenovirus fiber-cell interaction: adenovirus type $2(\operatorname{Ad} 2)$ and Ad9 utilize the same cellular fiber receptor but use different binding strategies for attachment. J. Virol. 70:7614-7621.

21. Mathias, P., T. Wickham, M. Moore, and G. Nemerow. 1994. Multiple adenovirus serotypes use alpha $\mathrm{v}$ integrins for infection. J. Virol. 68:6811-6814.

22. Bai, M., L. Campisi, and P. Freimuth. 1994. Vitronectin receptor antibodies inhibit infection of HeLa and A549 cells by adenovirus type 12 but not by adenovirus type 2. J. Virol. 68:5925-5932.
23. Bai, M., B. Harfe, and P. Freimuth. 1993. Mutations that alter an ArgGly-Asp (RGD) sequence in the adenovirus type 2 penton base protein abolish its cell-rounding activity and delay virus reproduction in flat cells. J. Virol. 67: 5198-5205.

24. Wickham, T.J., E.J. Filardo, D.A. Cheresh, and G.R. Nemerow. 1994 Integrin alpha $\mathrm{v}$ beta 5 selectively promotes adenovirus mediated cell membrane permeabilization. J. Cell Biol. 127:257-264.

25. Seth, P. 1994. Adenovirus-dependent release of choline from plasma membrane vesicles at an acidic ph is mediated by the penton base protein. $J$. Virol. 68:1204-1206.

26. Goldman, M.J., and J.M. Wilson. 1995. Expressi

27. on of $a_{v} b_{5}$ integrin is necessary for efficient adenovirus-mediated gene transfer in the human airway. J. Virol. 69:5951-5958.

28. Smythe, W.R., H.C. Hwang, A.A. Elshami, K.M. Amin, S.M. Albelda, and L.R. Kaiser. 1995. Differential sensitivity of thoracic malignant tumors to adenovirus-mediated drug sensitization gene therapy. J. Thorac. Cardiovasc. Surg. 109:626-630.

29. Hautala, T., K. Vuori, P. Freimuth and M J. Welsh 1996. Role of av integrins and intracellular signaling in adenovirus-mediated gene transfer. Cold Spring Harbor Symp. Quant. Biol. (Abstr.)

30. Horwitz, M.S. 1990. Adenoviridae and their replication. In Virology. B.N. Fields, D.M. Knipe, et al., editors. Raven Press, Ltd., New York. 1679 1721.

31. Rich, D.P., L.A. Couture, L.M. Cardoza, V.M. Guiggio, D. Armentano, P.C. Espino, K. Hehir, M.J. Welsh, A.E. Smith, and R.J. Gregory. 1993. Development and analysis of recombinant adenoviruses for gene therapy of cystic fibrosis. Hum. Gene Ther. 4:461-476.

32. Kondo, M., W.E. Finkbeiner, and J.H. Widdicombe. 1991. Simple technique for culture of highly differentiated cells from dog tracheal epithelium. Am. J. Physiol. 261:L106-L117.

33. Berry, M.N., and D.S. Friend. 1969. High-yield preparation of isolated rat liver parenchymal cells. J. Cell Biol. 43:506-520.

34. Welsh, M.J., J. Zabner, S.M. Graham, A.E. Smith, R. Moscicki, and S.C. Wadsworth. 1995. Adenovirus-mediated gene transfer for cystic fibrosis. Part A. Safety of dose and repeat administration in the nasal epithelium. Part B. Clinical efficacy in the maxillary sinus. Hum. Gene Ther. 6:205-218.

35. Pickles, R.J., P.M. Barker, H. Ye, and R.C. Boucher. 1996. Efficient adenovirus-mediated gene transfer to basal but not columnar cells of cartilaginous airway epithelia. Hum. Gene Ther. 7:921-931.

36. Breeze, R.G., and R.B. Wheeldon. 1977. The cells of the pulmonary airways. Am. Rev. Respir. Dis. 116:705-777.

37. Kasahara, N., A.M. Dozy, and Y.W. Kan. 1994. Tissue-specific targeting of retroviral vectors through ligand-receptor interactions. Science (Wash. DC). 266:1373-1376.

38. Wickham, T.J., P.W. Roelvink, D.E. Brough, and I. Kovesdi. 1996. Adenovirus targeted to heparan-containing receptors increases its gene delivery efficiency to multiple cell types. Nature Biotechnol. 14:1570-1573.

39. Douglas, J., B.E. Rogers, M.E. Rosenfeld, S.I. Michael, M. Feng, and D.T. Curiel. 1996. Targeted gene delivery by tropism-modified adenoviral vectors. Nature Biotechnol. 14:1-4.

40. Bergelson, J.M., J.A. Cunningham, G. Droguett, E.A. Kurt-Jones, A. Krithivas, J.S. Hong, M.S. Horwitz, R.L. Crowell, and R.W. Finberg. 1997. Isolation of a common receptor for Coxsackie B viruses and adenoviruses 2 and 5 . Science (Wash. DC). 275:1320-1323. 